\title{
Characterizing classes of fibromyalgia within the continuum of central sensitization syndrome
}

This article was published in the following Dove Press journal: Journal of Pain Research

\author{
Fred Davis' \\ Mark Gostine ${ }^{2}$ \\ Bradley Roberts' \\ Rebecca Risko' \\ Joseph C Cappelleri ${ }^{3}$ \\ Alesia Sadosky ${ }^{4}$ \\ 'ProCare Systems Inc, Grand Rapids, \\ MI, USA; ${ }^{2}$ Michigan Pain Consultants, \\ Grand Rapids, MI, USA; ${ }^{3}$ Statistics, \\ Pfizer Inc., New York, NY, USA; \\ ${ }^{4}$ Patient and Health Impact Pfizer Inc., \\ Groton, CT, USA
}

Background: While fibromyalgia (FM) is characterized by chronic widespread pain and tenderness, its presentation among patients as a continuum of diseases rather than a single disease contributes to the challenges of diagnosis and treatment. The purpose of this analysis was to distinguish and characterize classes of FM within the continuum using data from chronic pain patients.

Methods: FM patients were identified from administrative claims data from the ProCare Systems' network of Michigan pain clinics between January 1999 and February 2015. Identification was based on either use of traditional criteria (ie, ICD-9 codes) or a predictive model indicative of patients having FM. Patients were classified based on similarity of comorbidities (symptom severity), region of pain (widespread pain), and type and number of procedures (treatment intensity) using unsupervised learning. Text mining and a review of physician notes were conducted to assist in understanding the FM continuum.

Results: A total of 2,529 FM patients with 79,570 observations or clinical visits were evaluated. Four main classes of FM patients were identified: Class 1) regional FM with classic symptoms; Class 2) generalized FM with increasing widespread pain and some additional symptoms; Class 3) FM with advanced and associated conditions, increasing widespread pain, increased sleep disturbance, and chemical sensitivity; and Class 4) FM secondary to other conditions.

Conclusion: FM is a disease continuum characterized by progressive and identifiable classifications. Four classes of FM can be differentiated by pain and symptom severity, specific comorbidities, and use of clinical procedures.

Keywords: fibromyalgia, severity, comorbidities, clinical procedures, predictive modeling, disease progression, machine learning

\section{Introduction}

Fibromyalgia (FM) is considered a chronic, musculoskeletal pain condition of clinical complexity that likely arises from a dysfunction of central pain processing pathways. ${ }^{1,2}$ It is typically accompanied by sleep disturbance, anxiety/depression, and cognitive effects in addition to the cardinal symptoms of widespread musculoskeletal pain, joint stiffness, and fatigue. ${ }^{3,4}$ The well-recognized burdens associated with FM include impairment of daily function and reductions in quality of life from the patient perspective, as well as a range of comorbid conditions, high health care resource utilization, and associated costs from the clinical and economic perspectives, with these burdens increasing as FM severity increases. ${ }^{5,6}$

Diagnosing FM remains challenging, since neither imaging techniques nor laboratory tests are currently available that can clinically identify or confirm an FM diagnosis.
ProCare Pain Solutions, 6I Commerce Ave SW, Grand Rapids, MI 49503, USA

Tel + I 6169403504

Email rrisko@procarepain.com 
Criteria developed by the American College of Rheumatology (ACR) have traditionally been used for clinical diagnosis and severity classification of FM. The 2010 ACR criteria, ${ }^{7}$ which relied on scales that evaluated the extent of widespread pain (Widespread Pain Index) and the severity of specific somatic symptoms (symptom severity scale) have recently been updated to include a generalized pain criterion. ${ }^{8}$

Currently, there is no specific single International Classification of Diagnoses Ninth Revision, Clinical Modification (ICD-9-CM) billing code for FM, and the generally accepted diagnosis code that has been used in the medical literature is 729.1 , even though this code is designated as "Myositis and Myalgia, unspecified" and can include other conditions. Thus, when used in clinical or database studies, a diagnosis based strictly on this code may inaccurately reflect the actual number of patients with FM. A previous analysis compared FM characteristics among patients identified in a community-based chronic pain cohort based on this ICD-9 coding with characteristics of patients identified using novel predictive modeling, with the models based on diagnoses and characteristics relevant to FM that were considered potential predictors. ${ }^{9}$ While characteristics of the populations were generally similar between the two methods of identifying patients, predictive modeling identified a larger FM population. However, FM has long been proposed as a disease that presents as a continuum rather than a homogeneous entity. ${ }^{10}$ Within this continuum, it has been considered that both chronicity and symptom subgroups contribute to the observed heterogeneity, ${ }^{11-16}$ and that the presence of psychological and systemic components, in particular, potentially exacerbates the pain experience. ${ }^{17}$ While several of these studies were cluster analyses that identified clinical subgroups based on symptom presentation, a broader approach to characterizing the FM continuum has been lacking.

More recently, variables associated with health care resource utilization were determined to be predictive of an FM diagnosis, suggesting the importance of variables beyond those related to clinical presentation. ${ }^{18}$ Furthermore, another study, by Rodero et al, ${ }^{12}$ classified FM patients into three groups based on disease duration (ie, 6 months to 2 years; $2-4$ years; $>4$ years), suggesting that disease course may be a relevant variable for determining treatment modalities; once FM becomes more centralized, some treatment options may be more warranted than others. Since a greater understanding of the FM continuum across a broad clinical perspective may enhance understanding of the disease and its treatment, the objective of this study was to provide a first step toward systematically identifying and describing classes of FM.

\section{Methods}

For this retrospective analysis, de-identified clinic-level data were provided by the ProCare Systems network of chronic pain clinics in Michigan of patients who had already presented to the clinics between January 1999 and February 17, 2015. ProCare Systems, a management organization specializing in chronic pain, has a network of 11 chronic pain sites in Michigan. Since 2008, physicians managed by ProCare have used the PRISM ${ }^{\mathrm{TM}}$ Care Management System for assessing the impact of disease on the well-being of an individual in their managed office-based pain practices to provide personalized treatment. All data for the current analysis were fully compliant with the Health Insurance Portability and Accountability Act and exempt from IRB Review according to 45 CFR 46.101 HHS.

At the time of this research, there was no single specific ICD code for FM. Therefore, patients with FM in the ProCare Systems' network of clinics from January 1999 to February 17, 2015 were identified as previously described: either 1 year of physician-assigned ICD-9 code 729.1 ("myositis and myalgia, unspecified") with two codes separated at least 1 year apart and a length of treatment $\geq 365$ days, or using a predictive model. ${ }^{9,19}$ Patients were also required to have a combination of more than two office visits, Pain Health Assessments (PHA; ProCare Systems, Inc.; a patient selfassessment instrument) or prescription medications used to treat FM.

FM-related variables included in the analysis are shown in Table S1 and were derived from several sources including guidelines that suggested their role in the diagnosis or presentation of FM., ${ }^{3,7,9,18}$ Classes of FM were categorized based on disease duration and/or severity. The prevalence and magnitude of variables were analyzed longitudinally by application of unsupervised learning procedures, which relies on an algorithm for imputing relevant patterns among the input data, for classification as shown in Figure $1 .^{20}$ Since a previous study suggested the potential utility of a time-series analysis, ${ }^{12} \mathrm{~K}$-means clustering was used to form similar categories or groups from unlabeled data, and principal components analysis was applied to variables that occur or change over time.

Discriminant analysis was used to provide descriptive and predictive components of FM that were identified as unique and distinct FM classes. The benefit of using discriminant analysis descriptively is the ability to distinguish the variables that contribute significantly to the differences among classes. Class reassignment was performed if there appeared to be a transition between classes that occurred $<110$ days, 


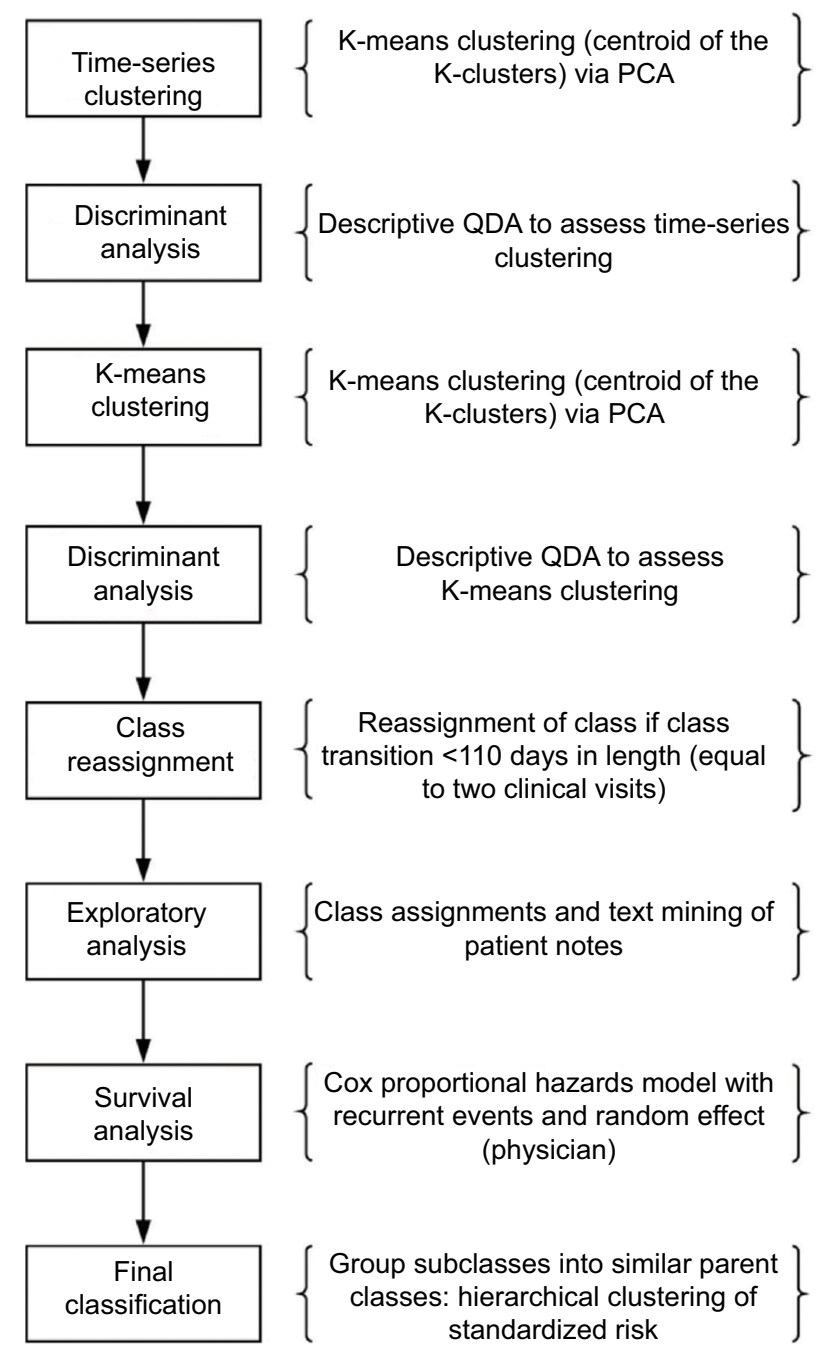

Figure I Flowchart of methods.

Abbreviations: PCA, principal components analysis; QDA, quadratic discriminant analysis.

the average between two clinical visits. The 110-day value was considered clinically relevant based on an assumed need for a physician visit because of a change in disease status.

Exploratory survival analysis further investigated class reassignment based on data from text mining of the field for patient history from the physician's notes. The text was broken down into individual words, bigrams (two words), and trigrams (three words), which were subsequently flagged when a comorbidity or disease of interest was mentioned in the patient notes. Negation rules were applied to ensure that the account in the notes did not rule out a particular condition or comorbidity. This text mining was used to more clearly identify and define comorbidities, traumatic events, and secondary conditions that were not available in the claims database. These additional conditions were then confirmed by patient chart review. Survival analysis was conducted to elucidate the results of the classification procedures. Specifically, a Cox proportional hazards model was implemented that included recurrent events and incorporated a random effect for physician. This model assessed the risk of the relevant variables associated with the key characteristics including 1) symptom severity and comorbidities; 2) widespread pain; 3) secondary diseases and conditions obtained from the physician's notes; and 4) treatment intensity represented by the summation of procedures over time. Finally, a network analysis was used to analyze the interconnected components to provide understanding of their relationship and potential sources of transition between identified classifications.

\section{Results}

A total of 2,529 patients $(76.3 \%$ female, $23.7 \%$ male $)$ were identified who had 79,570 observations, defined as anything that could be considered an interaction between a provider and patients including prescription refills, phone contacts, or clinical visits between January 1999 and February 17, 2015. Of these patients, 165 met the ACR criteria for traditional ICD selection, 1,510 for the predictive model, and 854 patients overlapped both selection criteria.

Nine classes were identified; however, the K-means classification also suggested four subclasses. Discriminant analysis found that time did not contribute significantly to the FM patient classification $(P>0.05)$. When the sequence of analyses was repeated excluding time as a factor, it was observed that a large portion of the reclassified observations was dependent on either a temporal component due to disease progression resulting in transitions across classes or misclassification of patients. This was corrected through text mining of physician notes, and revealed a more distinct separation from the other classes.

Heat maps characterizing the likelihood and severity of the nine FM subclasses identified from K-means classification were constructed based on the presence and importance of each of the variables and are shown in Figure 2. From these characterizations, four parent classes of FM were identified as being indicative of progressive disease based on severity, comorbidities, and the type and number of clinical procedures. Table 1 summarizes the differences among the classes with regard to comorbidities, body region, secondary conditions, and clinical procedures, and shows that the subclasses could be ordered by increasing severity based on their sensitivity to small changes in the evaluated variables associated with FM (ie, comorbidities, regions of pain, and procedures).

While sex was similar across the parent classes (Table 1), some differences were noted for age. In particular, Class 1 


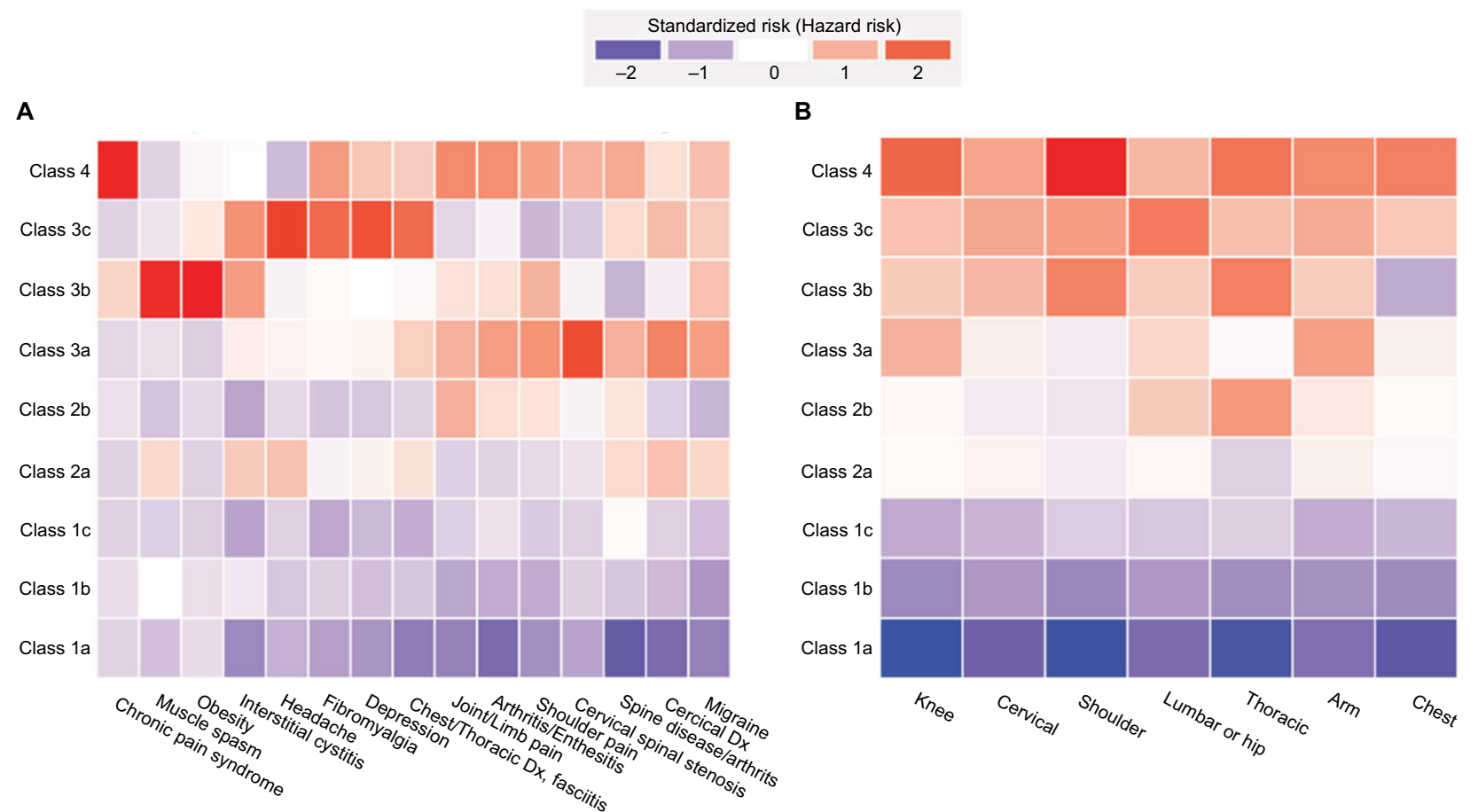

C

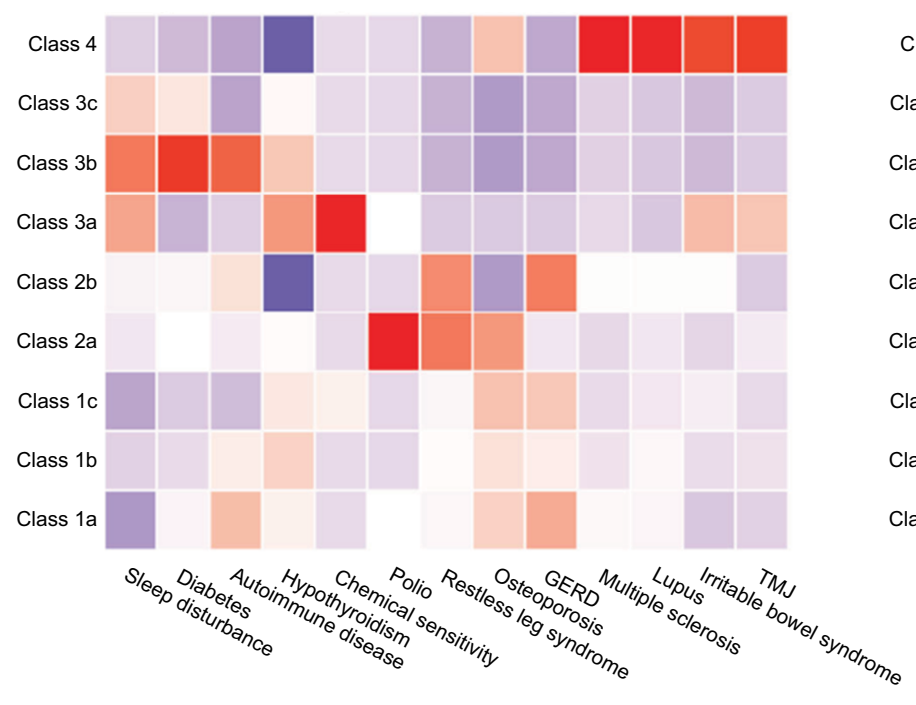

D

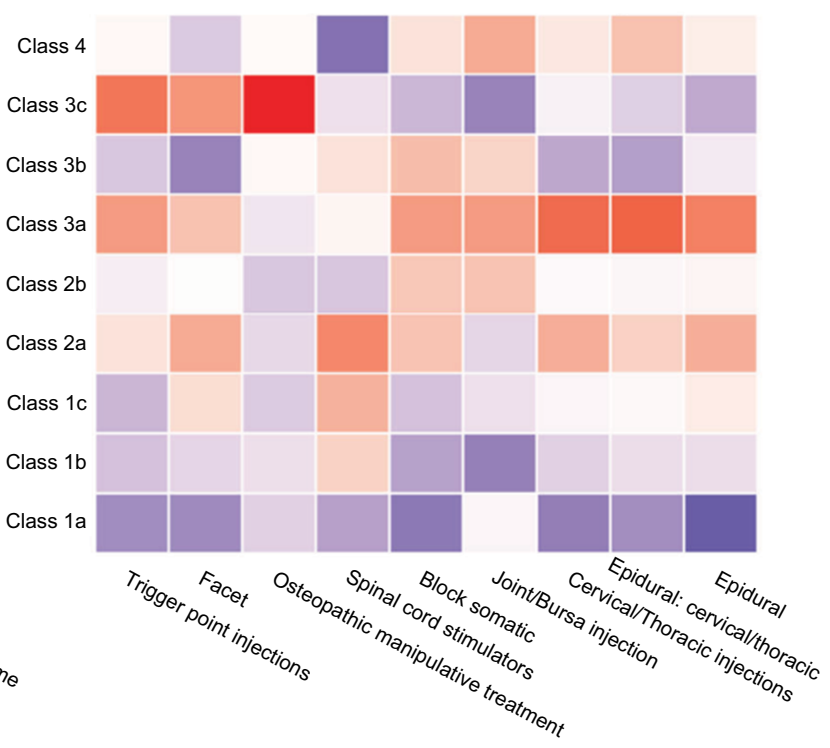

Figure 2 Heat map of the standardized risk of the fibromyalgia classes, expressed as standard deviations above or below the mean, identified by unsupervised learning. Notes: (A) Comorbidities and symptom severity. (B) Widespread pain. (C) Secondary diseases and conditions obtained from the health history field of the patient note within the electronic health record. (D) Treatment intensity, as represented by interventional procedures.

Abbreviations: TMJ, temporomandibular disorder; GERD, gastroesophageal reflux disease.

was characterized by a younger demographic relative to the other classes except for Class 4 males, who were the youngest of the four classes.

During analysis of the temporal component, it was found that some patients exhibited characteristics of transitioning to the next class of FM, and then at the next visit, were reassigned to the class in which they belonged to previously. A network analysis was conducted to better understand the transitions among the classes. This network analysis used the assumption that a patient would have to sustain the same class for at least 110 days (equal to the average time for two visits) before transitioning, which ensured consistency. Most transitions followed a fairly linear, progressive course where patients started in Class 1a and progressed through to Class 1c (Figure 3A). From this point, transitions were driven by specific comorbidities or symptom severity, the extent of widespread pain, and secondary conditions. In addition, once patients entered these other classes, there was accelerated 
Table I FM classes

\begin{tabular}{|c|c|c|c|c|c|c|}
\hline Class & Description & $\begin{array}{l}\text { Demographics: } \\
\text { sex, \%; age, mean } \\
\text { (SD) }\end{array}$ & $\begin{array}{l}\text { Main } \\
\text { comorbidities }\end{array}$ & $\begin{array}{l}\text { Body region } \\
\text { prominence }\end{array}$ & $\begin{array}{l}\text { Main } \\
\text { secondary } \\
\text { conditions }\end{array}$ & $\begin{array}{l}\text { Main treatment } \\
\text { focus }\end{array}$ \\
\hline $\begin{array}{l}\text { I. With three } \\
\text { subclasses }\end{array}$ & $\begin{array}{l}\text { Regional FM with } \\
\text { classic symptoms }\end{array}$ & $\begin{array}{l}77.9 \% \text { females, } 55.3 \\
(16.5) \text { years; } 22.1 \% \\
\text { males, } 55.4(16.5) \\
\text { years }\end{array}$ & $\begin{array}{l}\text { Interstitial cystitis, } \\
\text { muscle spasm, } \\
\text { spinal arthritis }\end{array}$ & $\begin{array}{l}\text { Knee, cervical, } \\
\text { shoulder, arm, } \\
\text { chest }\end{array}$ & $\begin{array}{l}\text { GERD, } \\
\text { osteoporosis, } \\
\text { RLS }\end{array}$ & $\begin{array}{l}\text { Facets and spinal cord } \\
\text { stimulators }\end{array}$ \\
\hline $\begin{array}{l}\text { 2. With two } \\
\text { subclasses }\end{array}$ & $\begin{array}{l}\text { Generalized FM with } \\
\text { increasing widespread } \\
\text { pain and additional } \\
\text { symptoms }\end{array}$ & $\begin{array}{l}81.6 \% \text { females, } 61.4 \\
(17.3) \text { years; } 18.4 \% \\
\text { males, } 58.9(17.2) \\
\text { years }\end{array}$ & $\begin{array}{l}\text { Arthritis, upper } \\
\text { body/limb pain, } \\
\text { cervical conditions, } \\
\text { migraine }\end{array}$ & $\begin{array}{l}\text { Chest, lumbar/ } \\
\text { hip, and } \\
\text { significant } \\
\text { increase in knee }\end{array}$ & $\begin{array}{l}\text { GERD, RLS, } \\
\text { polio }\end{array}$ & $\begin{array}{l}\text { Epidurals, facets, spinal } \\
\text { cord stimulators, } \\
\text { bursa/trigger point } \\
\text { injections, cervical/ } \\
\text { thoracic injections }\end{array}$ \\
\hline $\begin{array}{l}\text { 3. With three } \\
\text { subclasses }\end{array}$ & $\begin{array}{l}\text { Advanced FM with } \\
\text { associated conditions, } \\
\text { increasing widespread } \\
\text { pain, increased sleep } \\
\text { disturbance, and } \\
\text { chemical sensitivity }\end{array}$ & $\begin{array}{l}74.2 \% \text { females, } 59.8 \\
(18.0) \text { years; } \\
25.8 \% \text { males, 6I.4 } \\
(21.4) \text { years }\end{array}$ & $\begin{array}{l}\text { Arthritis, upper } \\
\text { body/limb pain, } \\
\text { cervical conditions, } \\
\text { migraine }\end{array}$ & $\begin{array}{l}\text { Chest, lumbar/ } \\
\text { hip, and } \\
\text { significant } \\
\text { increase in knee }\end{array}$ & $\begin{array}{l}\text { GERD, RLS, } \\
\text { polio }\end{array}$ & $\begin{array}{l}\text { Epidurals, facets, spinal } \\
\text { cord stimulators, } \\
\text { bursa/trigger point } \\
\text { injections, cervical/ } \\
\text { thoracic injections }\end{array}$ \\
\hline $\begin{array}{l}\text { 4. With no } \\
\text { subclasses }\end{array}$ & $\begin{array}{l}\text { Secondary FM reactive } \\
\text { to disease }\end{array}$ & $\begin{array}{l}80.5 \% \text { females; 6I.3 } \\
(17.8) \text { years; 19.5\% } \\
\text { males, } 49.4(17.0) \\
\text { years }\end{array}$ & $\begin{array}{l}\text { Chronic pain } \\
\text { syndrome, joint/ } \\
\text { limb pain }\end{array}$ & Chest & $\begin{array}{l}\text { MS, lupus, TMJ, } \\
\text { IBS }\end{array}$ & $\begin{array}{l}\text { Joint and bursa } \\
\text { injections }\end{array}$ \\
\hline
\end{tabular}

Abbreviations: FM, fibromyalgia; GERD, gastroesophageal reflux disease; IBS, irritable bowel syndrome; MS, multiple sclerosis; TMJ, temporomandibular joint disorder; RLS, restless leg syndrome.

A

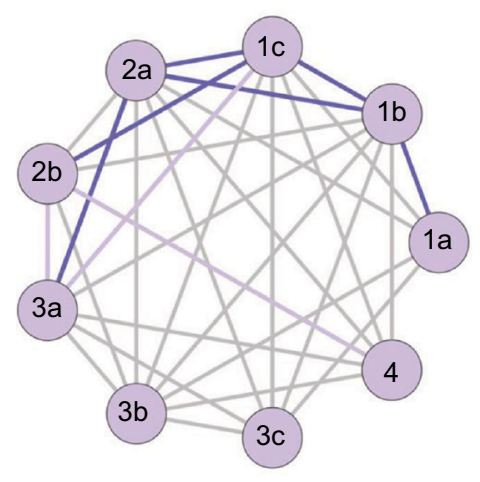

B

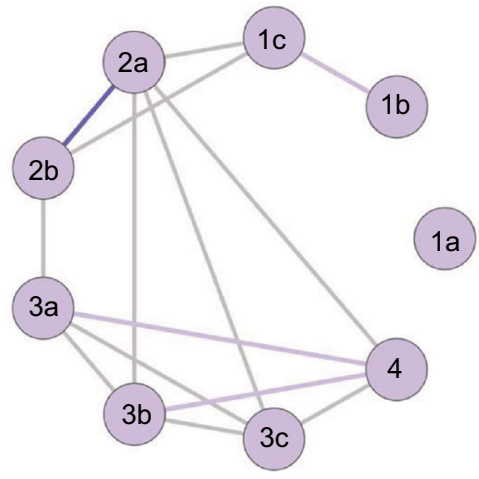

Figure 3 Transitions in fibromyalgia classes.

Notes: (A) Forward transitions. (B) Reverse transitions. Darker colors represent more frequently observed transitions.

progression through the classes that followed. Reverse transitions did not occur as frequently, but when they did occur it was generally within one of the four parent classes or when patients transferred from Class 4 (secondary FM) to Class 2 or 3 (Figure $3 \mathrm{~B}$ ).

The distribution of patients among classes (Figure 4) shows that Class 1 was the most prevalent, accounting for almost two-thirds (64\%) of the patients. There were lower proportions of patients in each subsequent class indicative of disease progression, with only $3 \%$ of the patient population in Class 4.

\section{Discussion}

This study enabled categorization of FM into four distinct classes that show a progressive relationship over time with regard to severity, comorbidities, and the type and number of clinical procedures. Implementation of an unsupervised approach $^{21}$ as done in this study highlights the inherent difficulty in determining class membership based solely on administrative claims data, as well as in the consideration of time in a complex disease like FM. In particular, one class was difficult to classify - Class 4 (secondary FM). This difficulty arose because the risk of comorbidities was accelerated 


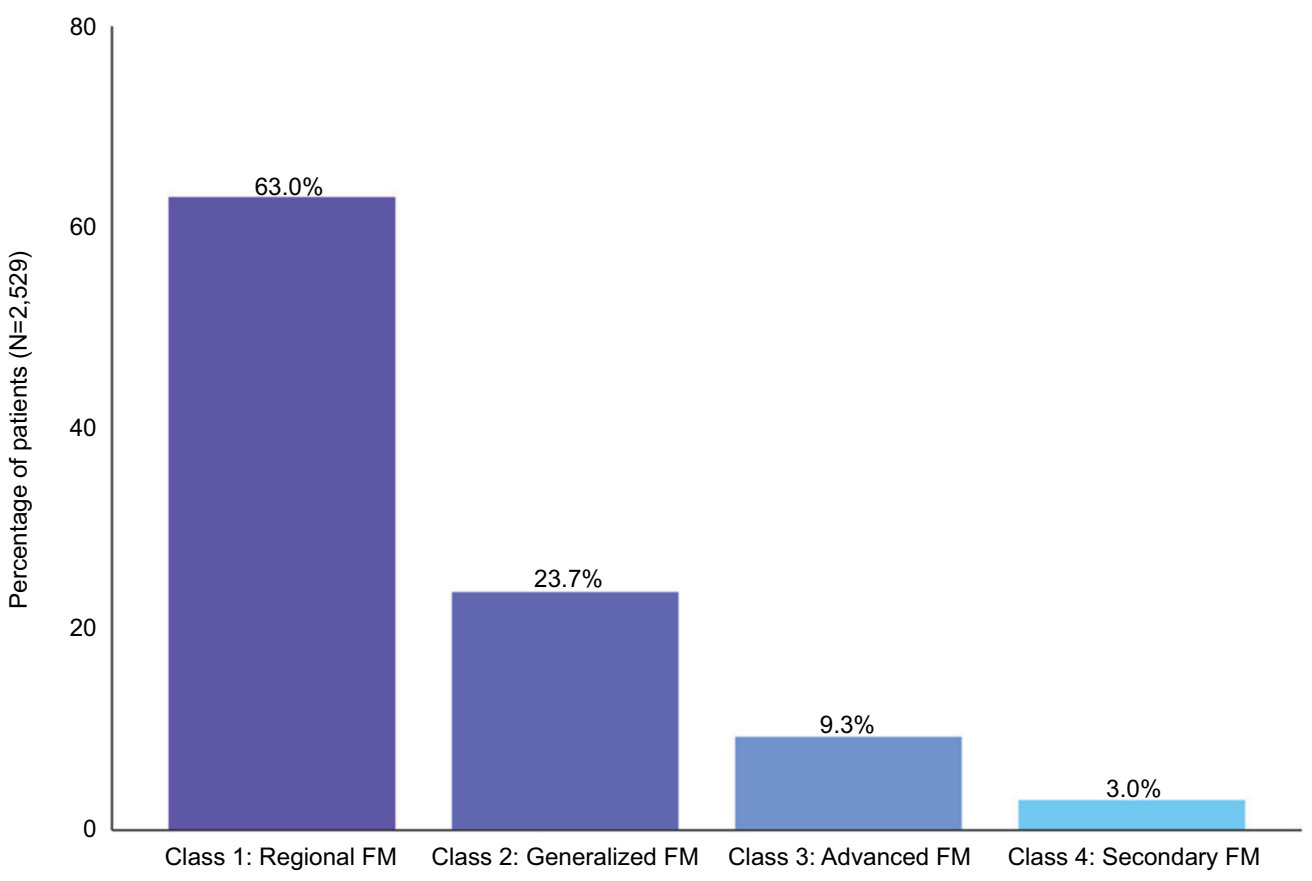

Figure 4 Patients from the identified population currently in characterized fibromyalgia classes $(\mathrm{N}=2,529)$.

Abbreviation: FM, fibromyalgia.

such that presentation of symptoms did not appear to entirely account for the elevated risk. The classification procedure without time more accurately separated these FM patients from the other classes, suggesting that the time component is too sensitive to small perturbations in the data. However, to understand the assignment of classes on a deeper level, a rigorous post hoc analysis of the classes was conducted, which resulted in further support that the classes represent a continuum that describes the progressive nature of FM. In this regard, it may also be proposed from a population perspective that current concepts of FM severity are restricted to the classical understanding of FM. Therefore, there also appears to be a need in the practical clinical setting to consider the possible presence of FM in patients with existing diseases, especially as the results reported here suggest, these patients seem to rapidly progress.

Class 1 can be considered regional FM within the classic symptoms of chronic widespread pain and joint tenderness that provided the initial foundation of diagnostic criteria, ${ }^{22}$ and Class 2 represents a more generalized FM. Since Class 2 is characterized by a broader range of body areas, a greater severity of widespread pain, and the presence of additional symptoms, it may be considered more closely related to the 2016 revised criteria. ${ }^{8}$ Thus, Classes 1 and 2 reflect the current concepts and major patient profile for FM. The identification of Classes 3 and 4, with a greater variety of symptoms and body regions affected, expands the concept of FM as a disease continuum rather than a set of symptoms that can be discretely evaluated and emphasizes the need for an individualized approach to diagnosis and treatment. Class 3 is associated with more advanced comorbidities, with further increases in pain relative to Classes 1 and 2. Class 3 patients are also characterized by a clear prevalence of sleep disturbance and potential chemical sensitivity that is manifested by a latex allergy as previously reported. ${ }^{9}$ In contrast to Classes 1-3, Class 4 has the highest prevalence and severity of widespread pain and symptoms. Class 4 appears to represent FM that is secondary to other diseases such as multiple sclerosis and lupus, which have a high prevalence in this class.

FM classes based on presence and severity of symptoms and comorbidities are consistent with studies that have investigated symptom clusters in FM patients. ${ }^{13-16}$ This consistency in identifying classes demonstrates the heterogeneity in presentation that characterizes FM as a continuum, with the observed transitions further supporting this concept. From these classes, especially those indicative of greater FM severity, similarities are being observed across comorbid conditions such as sleep disturbance, irritable bowel syndrome, and restless leg syndrome, which have long been recognized as conditions frequently reported by FM patients. ${ }^{23}$ These parallels may be especially relevant in Class 4 patients in whom FM may be secondary to other disease states. 
Clinical context is provided by the heat maps (Figure 4), which not only indicate that treatment intensity seemed to be the "highest" at the start of the class but also that the standardized risk (hazard ratio), which is indicated by increments of $1 \mathrm{SD}$ and can thus be considered clinically significant, is greater in the later classes of FM. These can be interpreted as the comorbidities, and indeed, all the variables shown in the heat maps are more pronounced relative to more generalized forms of FM. While comorbidity and symptom severity may be difficult to characterize in an individual patient, the heat maps suggest profiles that may be used for individualized treatment strategies as has been suggested previously. ${ }^{24}$ These observations also support the concept of FM as a condition of centralized pain, and that this pain becomes more centralized over the disease course, ${ }^{17}$ thus potentially requiring approaches to management that reflect the degree of centralization as identified by the FM classes.

\section{Limitations}

A limitation of this study that may potentially be criticized is the assumption in the analysis that a patient would have to sustain the same class for at least 110 days (equal to the average time for two visits) before transitioning to the next class. This assumption was applied to minimize the impact of differences in billing codes that were not carried forward in subsequent patient encounters. Additionally, the time period spanned 15 years, and changes in how FM was defined and coded over this period were not included as variables in the analyses. Further work is warranted to provide a confirmatory approach using the same sample of patients, as well as a newly identified sample.

\section{Conclusion}

FM may be represented as a disease continuum, with identifiable classes and subclasses based on pain and symptom severity, specific comorbidities, and use of clinical procedures. Patients demonstrated increases in symptom severity and region of pain by class, suggesting that the FM continuum tracks with disease progression over time. Additional studies are warranted to evaluate and better define the classes by severity with the goal of informing potential approaches to patient evaluation and management. Such an understanding and characterization of how FM patients progress through their disease may enhance diagnosis and help optimize treatment, potentially leading to improved patient outcomes and reductions in the health care system burden.

\section{Disclosure}

This study was sponsored by Pfizer. JCC and AS are employees of Pfizer, the sponsor of this study. FD, BR, and RR are employees of ProCare Systems, Inc., which received funding from Pfizer for conducting the analyses. MG collaborated with Pfizer on this project; he was not financially compensated for his participation or the development of this manuscript. Editorial support was provided by E. Jay Bienen and was funded by Pfizer.

\section{References}

1. Clauw DJ, Arnold LM, McCarberg BH. The science of fibromyalgia. Mayo Clin Proc. 2011;86(9):907-911.

2. Halpern R, Shah SN, Cappelleri JC, Masters ET, Clair A. Evaluating guideline-recommended pain medication use among patients with newly diagnosed fibromyalgia. Pain Pract. 2015;16(8):1027-1039.

3. Bennett RM. Clinical manifestations and diagnosis of fibromyalgia. Rheum Dis Clin North Am. 2009;35(2):215-232.

4. Kravitz HM, Katz RS. Fibrofog and fibromyalgia: a narrative review and implications for clinical practice. Rheumatol Int. 2015;35(7): 1115-1125.

5. Schaefer C, Chandran A, Hufstader M, et al. The comparative burden of mild, moderate and severe fibromyalgia: results from a cross-sectional survey in the United States. Health Qual Life Outcomes. 2011;9(1):71.

6. Chandran A, Schaefer C, Ryan K, Baik R, McNett M, Zlateva G. The comparative economic burden of mild, moderate, and severe fibromyalgia: results from a retrospective chart review and cross-sectional survey of working-age U.S. adults. J Manag Care Pharm. 2012;18(6): 415-426.

7. Wolfe F, Clauw DJ, Fitzcharles M-A, et al. The American College of Rheumatology Preliminary Diagnostic Criteria for Fibromyalgia and Measurement of Symptom Severity. Arthritis Care Res. 2010;62(5):600-610.

8. Wolfe F, Clauw DJ, Fitzcharles MA, et al. 2016 Revisions to the 2010/2011 fibromyalgia diagnostic criteria. Semin Arthritis Rheum. 2016;46(3):319-329.

9. Gostine M, Davis F, Roberts BA, et al. Clinical characteristics of fibromyalgia in a chronic pain population. Pain Pract. 2018;18(1):67-78.

10. Wolfe F. The relation between tender points and fibromyalgia symptom variables: evidence that fibromyalgia is not a discrete disorder in the clinic. Ann Rheum Dis. 1997;56(4):268-271.

11. Giesecke T, Williams DA, Harris RE, et al. Subgrouping of fibromyalgia patients on the basis of pressure-pain thresholds and psychological factors. Arthritis Rheum. 2003;48(10):2916-2922.

12. Rodero B, Casanueva B, García-Campayo J, Roca M, Magallón R, del Hoyo YL. Stages of chronicity in fibromyalgia and pain catastrophising: a cross-sectional study. BMC Musculoskelet Disord. 2010;11:251.

13. Bennett RM, Russell J, Cappelleri JC, Bushmakin AG, Zlateva G, Sadosky A. Identification of symptom and functional domains that fibromyalgia patients would like to see improved: a cluster analysis. BMC Musculoskelet Disord. 2010;11:134.

14. Vincent A, Hoskin TL, Whipple MO, et al. OMERACT-based fibromyalgia symptom subgroups: an exploratory cluster analysis. Arthritis Res Ther. 2014;16(5):463.

15. Salaffi F, Mozzani F, Draghessi A, et al. Identifying the symptom and functional domains in patients with fibromyalgia: results of a cross-sectional Internet-based survey in Italy. J Pain Res. 2016;9: 279-286.

16. Yim YR, Lee KE, Park DJ, et al. Identifying fibromyalgia subgroups using cluster analysis: relationships with clinical variables. Eur J Pain. 2017;21(2):374-384.

17. Sluka KA, Clauw DJ. Neurobiology of fibromyalgia and chronic widespread pain. Neuroscience. 2016;338:114-129.

18. Emir B, Masters ET, Mardekian J, Clair A, Kuhn M, Silverman SL. Identification of a potential fibromyalgia diagnosis using random forest modeling applied to electronic medical records. J Pain Res. $2015 ; 8: 277-288$. 
19. Juckett DA, Davis FN, Gostine M, Reed P, Risko R. Patient-reported outcomes in a large community-based pain medicine practice: evaluation for use in phenotype modeling. BMC Med Inform Decis Mak. 2015; $15: 41$.

20. Hastie T, Tibshirani R, Friedman J. The Elements of Statistical Learning: Data Mining, Inference, and Prediction. 2nd ed. New York: Springer Science+Business Media; 2013.

21. Pan W, Shen X, Liu B. Cluster analysis: unsupervised learning via supervised learning with a non-convex penalty. J Mach Learn Res. 2013;14(7):1865.
22. Wolfe F, Smythe HA, Yunus MB, et al. The American College of Rheumatology 1990 Criteria for the Classification of Fibromyalgia. Report of the Multicenter Criteria Committee. Arthritis Rheum. 1990;33(2):160-172.

23. Bennett RM, Jones J, Turk DC, Russell IJ, Matallana L. An internet survey of 2,596 people with fibromyalgia. BMC Musculoskelet Disord. 2007;8(1):27.

24. Häuser W, Perrot S, Clauw DJ, Fitzcharles M-A. Unravelling fibromyalgia - steps toward individualized management. J Pain. 2018;19(2):125-134 


\section{Supplementary material}

Table SI Variables included in the analyses

\begin{tabular}{|c|c|c|c|}
\hline Variable & Role & Data source & Operational definition \\
\hline \multicolumn{4}{|l|}{ Case/control variable } \\
\hline Fibromyalgia & Predictor, outcome & Claims database & Primary, secondary \\
\hline \multicolumn{4}{|l|}{ Clinical comorbidity variables by physician diagnosis } \\
\hline Arthritis/enthesitis & Comorbidity, predictor & Claims database & Primary \\
\hline Cervical disorders & Comorbidity, predictor & Claims database & Primary \\
\hline Cervical spinal stenosis & Comorbidity, predictor & Claims database & Primary \\
\hline Chronic pain syndrome & Comorbidity, predictor & Claims database & Primary \\
\hline Coccygodynia & Comorbidity, predictor & Claims database & Primary \\
\hline Headache & Comorbidity, predictor & Claims database & Primary \\
\hline Interstitial cystitis & Comorbidity, predictor & Claims database & Primary \\
\hline Limb/joint pain & Comorbidity, predictor & Claims database & Primary \\
\hline Migraine & Comorbidity, predictor & Claims database & Primary \\
\hline Muscle spasm & Comorbidity, predictor & Claims database & Primary \\
\hline Obesity & Comorbidity, predictor & Claims database & Primary \\
\hline Rheumatoid arthritis & Comorbidity, predictor & Claims database & Primary \\
\hline Spinal disease/arthritis & Comorbidity, predictor & Claims database & Primary \\
\hline Shoulder pain & Comorbidity, predictor & Claims database & Primary \\
\hline \multicolumn{4}{|l|}{ Clinical comorbidity variables by psychological diagnosis } \\
\hline Depression (depression and major depressive disorder) & Comorbidity, predictor & Claims database & Primary \\
\hline \multicolumn{4}{|l|}{ Health care resource utilization variables by procedure } \\
\hline Block somatic & Outcome & Claims database & Secondary \\
\hline Epidural & Outcome & Claims database & Secondary \\
\hline Epidural: cervical/thoracic & Outcome & Claims database & Secondary \\
\hline Facet & Outcome & Claims database & Secondary \\
\hline Facet: cervical/thoracic & Outcome & Claims database & Secondary \\
\hline Ilioinguinal injection & Outcome & Claims database & Secondary \\
\hline Joint/Bursa injection & Outcome & Claims database & Secondary \\
\hline Osteopathic manipulative treatment & Outcome & Claims database & Secondary \\
\hline Physical therapy & Outcome & Claims database & Secondary \\
\hline Trigger point injection & Outcome & Claims database & Secondary \\
\hline \multicolumn{4}{|l|}{ Patient-reported outcomes } \\
\hline Physical functioning impairment & Outcome & PHA & Primary, secondary \\
\hline Lower body impairment & Outcome & PHA & Primary, secondary \\
\hline Upper body impairment & Outcome & PHA & Primary, secondary \\
\hline Head and neck impairment & Outcome & PHA & Primary, secondary \\
\hline Perceived pain impairment & Outcome & PHA & Primary, secondary \\
\hline Pain & Outcome, mediator & PHA & Primary, secondary \\
\hline Emotional functioning impairment & Outcome & PHA & Primary, secondary \\
\hline Anger & Outcome & PHA & Primary, secondary \\
\hline Anxiety & Outcome & PHA & Primary, secondary \\
\hline Depression & Outcome & PHA & Primary, secondary \\
\hline Distress & Outcome & PHA & Primary, secondary \\
\hline Fatigue & Outcome & PHA & Primary, secondary \\
\hline Life control impairment & Outcome & PHA & Primary, secondary \\
\hline Tension & Outcome & $\mathrm{PHA}$ & Primary, secondary \\
\hline Vigor impairment & Outcome & PHA & Primary, secondary \\
\hline Perceived social interference & Outcome & PHA & Primary, secondary \\
\hline Percent relief & Outcome & PHA & Primary, secondary \\
\hline Quality of life impairment & Outcome & PHA & Primary, secondary \\
\hline Quality of sleep impairment & Outcome & PHA & Primary, secondary \\
\hline \multicolumn{4}{|l|}{ Number of pain regions by procedure location } \\
\hline Arm & Outcome & Claims database & Primary \\
\hline Cervical & Outcome & Claims database & Primary \\
\hline
\end{tabular}


Table SI (Continued)

\begin{tabular}{|c|c|c|c|}
\hline Variable & Role & Data source & Operational definition \\
\hline Chest & Outcome & Claims database & Primary \\
\hline Shoulder & Outcome & Claims database & Primary \\
\hline Thoracic & Outcome & Claims database & Primary \\
\hline Hip & Outcome & Claims database & Primary \\
\hline Knee & Outcome & Claims database & Primary \\
\hline \multicolumn{4}{|l|}{ Treatment activity markers } \\
\hline Unique procedures & Outcome & Claims database & Primary \\
\hline Total procedures & Outcome & Claims database & Primary \\
\hline Unique medications & Outcome & Claims database & Primary \\
\hline Total prescriptions & Outcome & Claims database & Primary \\
\hline Unique diagnoses & Outcome & Claims database & Primary \\
\hline Total diagnoses & Outcome & Claims database & Primary \\
\hline Total regions of pain ${ }^{a}$ & Outcome & Claims database & Primary \\
\hline Total regions of pain ${ }^{\mathrm{b}}$ & Outcome & Claims database & Primary \\
\hline Days between touch points & Outcome & Claims database & Primary \\
\hline Physician's rate of diagnosis & Outcome & Claims database & Primary \\
\hline
\end{tabular}

Notes: aPatient reported; 'Location of procedure.

Abbreviation: PHA, Pain Health Assessment.

\section{Publish your work in this journal}

The Journal of Pain Research is an international, peer reviewed, open access, online journal that welcomes laboratory and clinical findings in the fields of pain research and the prevention and management of pain. Original research, reviews, symposium reports, hypothesis formation and commentaries are all considered for publication.

\section{Dovepress}

The manuscript management system is completely online and includes a very quick and fair peer-review system, which is all easy to use. Visit http://www.dovepress.com/testimonials.php to read real quotes from published authors. 